Vol. 2, No. 1, pp. 32-36, 2021

\title{
Relationship between Perceived Ease of Use, Perceived Usefulness and Motivation Opportunity Ability Theory in Online Gamers Know-How Exchange
}

\author{
Bob Foster ${ }^{1}$, Fitriani Reyta ${ }^{2}$, Susan Purnama ${ }^{3}$ \\ ${ }^{1,2,3}$ Faculty of Economics and Business, Universitas Informatika dan Bisnis Indonesia, Indonesia
}

*Corresponding author email:bobriset@unibi.ac.id

\begin{abstract}
Business needs to take advantage of Indonesian online gamers who are using online community to communicate and interact, when gamers share their reviews of game, for example, or when they post reviews of their purchases of virtual goods from online games. Using online community, gamers can do the trading with other members. The key is to share their experience with online games throughout the gamer's journey. Players play an important role in the game market and have unique characteristics that respond differently to technology acceptance. In addition, a comprehensive review of the relevant literature on motivation for using Online Gamers Know-How Exchange shows that players are looking for recommendations from friends about the games they are interested in, through the social networking community and especially from their own communities. This paper analyzed the phenomenon of game-related industry involving motivation, opportunity, ability and technology acceptance model in which organizations effectively raise the communication and know how above the gamers. Gamers from online community game taken as sample in Bandung City, West Java, Indonesia. Result shown that the two PEOU and PU were positively related to Online Gamers Know-How Exchange.
\end{abstract}

Keywords: Online Gamers, Know-How Exchange, Perceived ease of Use, MOA, Perceived Usefulness.

\section{Introduction}

The online game is arguably one of the most successful business models on the Internet (Wu et al., 2013). Online games are one of the most prospective segments and have become a growing market sector in recent years (Lu and Wang et al., 2008; Koo, 2009). According to Herrewijn and Poels (2013), there are two business models used by the game industry in generating revenue of online games: Pay-to-play/Premium and Free-to-play. Pay-to-play/Premium is a business model where earnings are earned through the sale of access rights to play the games, where the access right can be physical - CDs, cassette, or digital service; Free-to-play, on the other hand, is a business model where users can download free game apps and play them. There are three categories in free-to-play: Shareware, players can access the trial game apps, it is to give players a chance to try the game and convince the player to buy the full version. Freemium, players can access the game apps for free, except for virtual content such as characters and features of game that can only be played by purchasing it. This Freemium model creates incomes through in-application deals where clients can buy extra characters or gear, for example, virtual merchandise (autos or weapons) that lift their exhibition and upgrade their gaming experience. This freemium type generally incorporates a huge extent of undecorated players. However, organizations produce incomes from selling adornments. Various kinds of frill are planned and evaluated in an unexpected way. This model makes more income than the regular paid-games mode (Wu et al., 2013). Lastly, Freeware is a category where players can access/download free gaming applications. Profits are not earned directly from players, but from in-game advertisements.

Past the game business, selling virtual things, likewise put in-game commercials has become a significant wellspring of income in the standard online administrations. This model where computerized items and 
administrations are usually used for the acknowledgment of monetary procedures is known as electronic business (electronic business). Concepts of web-based business identifies with a wide range of monetary movements that is executed online with the guide of electronic ICT advancements. Since the web-based game comprises of a few sections just as internet business, for example, online shops and virtual shopping arcades, it implies the dynamic development of web-based games and the potential outcomes of their usage in exchange make the chances of quickened development for the economy all in all. It is demonstrated that the game industry can't be isolated from the internet business industry, where one of the adaptation procedures should be possible through the web-based business stage.

Adaptation is a procedure that makes an item/administration has high financial esteem and can be utilized as a wellspring of salary. Adaptation in the internet games industry should be possible in three different ways incorporating paid notices contained in games, virtual things, and paid games (Kurniawan, 2016). In Indonesia, the entrance of the web-based gaming industry is energetically in accordance with the advancement of the web arrangement. In view of distributed information by the Indonesia Internet Service Provider Association (APJII) in 2017, there are 143.26 million individuals in Indonesia who utilize the web from absolute masses of 262 million individuals. A huge bit of the web clients in Indonesia is between 19-34 years old with the number arrived at an aggregate of 70.94 million individuals. The most common game genres in Indonesia with e-sports are real-time strategy (RTS), first person shooting (FPS), massively-multiplayer online (MMOG), and racing. The game competition is divided into three levels: amateur, semi-professional and professional. Some games that currently become the choice of Indonesian gamers are Hon, League of Legend, Dota, Point Blank and Counter Strike Online.

Perceived ease of use and perceived usefulness is assumed as the two established variable from Technology Acceptance Model that can be used to describe user acceptance or user decisions to use or adopt an information technology. The process of acceptance technology can occur in an online community where members share their knowledge. Similarly in the gaming community, especially online game, where members can exchange information about everything related to the game. Technology acceptance effectiveness will explain the effect of gamer's acceptance to use or adopt gaming towards the Community online. In light of the discernment that consumer to consumer online knowhow exchange fills in as a data source in regards to the item utilized, the Motivation Opportunity Ability (MOA) structure can likewise be utilized to clarify the degree in which online game players enter and take part up to date how trades with different gamers in the online network. Inspiration Opportunity Ability (MOA) hypothesis has been utilized to anticipate the consumer to consumer online knowhow exchange behavior the result revealed that MOA is particularly well-suited as a predictor of consumer to consumer online knowhow exchange (Briliana et al., 2015). Thusly, this examination expects to explore client to client online skill trade in Indonesia's games industry, focusing on online games. This examination intends to coordinate Perceived Ease of Use (PEU), Perceived Usefulness (PU) and Motivation, Opportunity, Ability (MOA) which have been used freely in past examinations in the examination of customer to customer Online Know-How Exchange.

Perceived Usefulness refers to the forthcoming client's conviction that embracing a given innovation will add to a superior presentation (Pinho and Soares, 2011). Perceived Ease of Use alludes to how much an individual anticipates no physical and mental challenges in receiving the current innovation (Pinho and Soares, 2011). In light of the MOA hypothesis, inspiration joins status, readiness, intrigue, and want to participate in data handling. Inspiration is additionally characterized as a part's longing or preparation to take part in know-how trade with different individuals (Gruen et al., 2006). Opportunity mirrors the degree to which a circumstance is helpful in accomplishing an ideal result or the absence of obstructions for accomplishing an ideal result (Gruen et al., 2006). In the MOA hypothesis, capacity has been conceptualized as the customers' abilities or proficiencies (MacInnis et al., 1991). Capacity can be characterized as the part's abilities or proficiencies to take part in know-how trades with different individuals (Gruen et al., 2006). Customer-to-Customer Know-How Exchange happens when clients interact with one another, trade information, contacts, process, concerns, grumblings, stories and additionally proposals that will improve their prosperity (Gruen et al., 2006), such as decision to purchase and word of mouth.

\section{Methodology}

The development of information technology one of them impact on computer games, where computer games can be played online (Ang et al., 2007; Hanson et al., 2005). Online games offer virtual gaming without geographical restrictions, so players can discuss and interact in various forums or online communities in real time. The increasing availability of online data provides a way to monitor and learn how users behave in online social systems and understand the characteristics that drive users to success, for example interactions in social media such as Facebook. This is refer to study which is attempt to explore and fill the gaps (level of knowledge among online gamers, differentiation of determinants of Customer to Customer Online Know-How Exchange in every country) in several esport topics and online game as subjects that became a research phenomenon, and to increase the popularity of 
eSports phenomenon (Hamari and Sjöblom 2015), virtual goods and gaming market (Hamari, 2015), and the increasing role of online reputation devices (Masum and Zhang 2004), such as ratings, reputation systems and reviews. Online gaming has a great sense of community; players need an online community dedicated to expressing their opinions or answering their questions about a particular game. In addition to the official website, many virtual gamer communities have become important communication channels through discussion forums, message boards, and chat rooms, this website can attract players.

Players play an important role in the game market and have unique characteristics that respond differently to technology acceptance. In addition, a comprehensive review of the relevant literature on motivation for using Customer to Customer Online Know-How Exchange shows that players are looking for recommendations from friends about the games they are interested in, through the social networking community and especially from their own communities. Several variables of TAM namely perceived ease of use (PEOU) - perceived usefulness (PU) and other variables, namely, motivation - opportunity - ability (MOA) have been identified from the literature as antecedents to Customer to Customer Online Know-How Exchange (Briliana et al., 2015).

Antecedents act as predictor variables against Customer to Customer Online Know-How Exchange. The theories, PEOU, PU and MOA theories are used as a basis for developing this research framework. A lot of research has been carried out in the context of information systems and mobile services (Liang and Yeh, 2011) to determine the factors that influence the adoption of an innovation or technology by consumers. Researchers in this context have widely used well established intention and behavioural models such as TRA, TPB, model related to acceptance of innovation like Innovation Diffusion Theory (IDT). Therefore, the researcher wants in this study to make the theory that has been previously described as a reference and direction in this research. The second theory used in this research is the application of a conceptual social marketing model, the MOA (motivation, opportunity and ability) framework (Rothschild, 1999), in the context of an online know-how exchange between Dota2 players. The motivation, opportunity, and ability (MOA) framework is proposed by MacInnis et al., (1991), which has the core that the level of marketing communication processing of an individual depends on three things, namely motivation, opportunity and ability. The effectiveness of a message can be achieved by developing one's motivation, opportunity, and ability (MOA) level. The MOA framework is developed with a different approach from the previous attitude model, which is by emphasizing more antecedents of information processing.

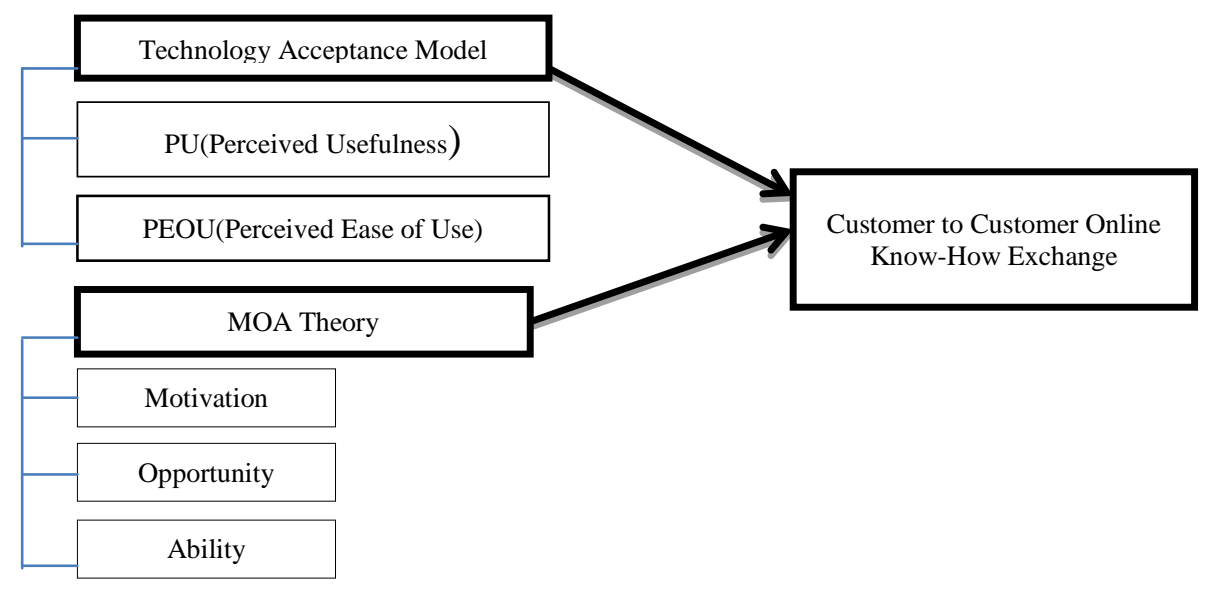

Figure 1. The Model of Research Framework

This paper discusses the current phenomenon of game-related industry involving broad social activities, in which organizations effectively utilize social marketing strategies for marketing. These resources should be utilized to produce effectiveness directed at those who are most responsive and will adopt and maintain the desired social behavior appropriately. The model adapts and applies the motivation, opportunity, and ability (MOA) theory to explain levels of Online Gamers Know-How Exchange.

\section{Results and Discussion}

Figure 2 are the result of hypothesis testing using PLS-SEM method and run by SMART PLS Software, 300 gamers from online game community in Bandung City taken as sample by quota sampling. 


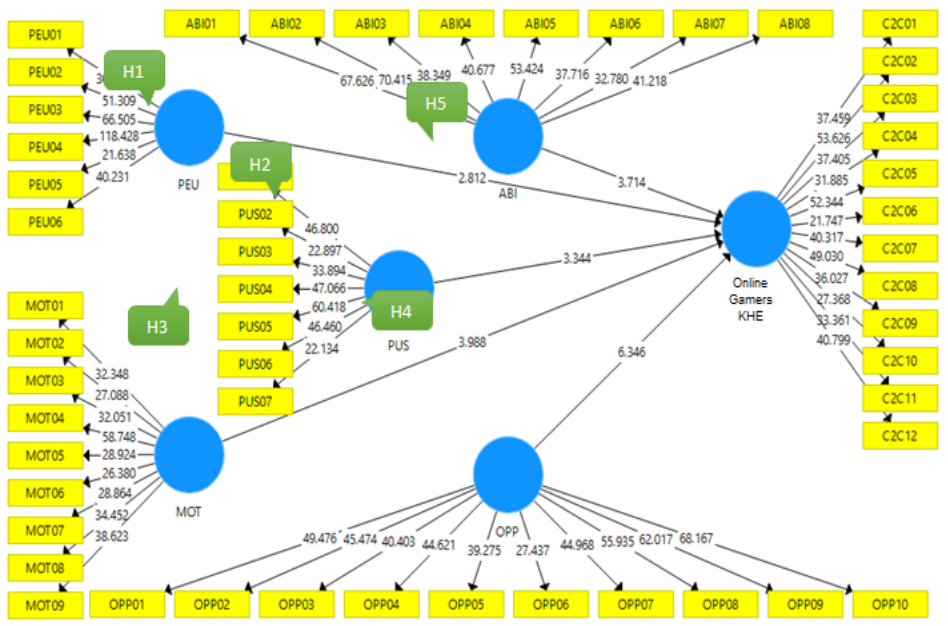

Figure 2. PLS-SEM Result Run by SMART PLS

Figure 2 shown that the two PEOU and PU were positively related to Online Gamers Know-How Exchange. A number of studies have used the PEOU and PU to understand technology adoption decisions involving the Internet and online applications, including e-mail and e-learning (Chin,1998; Gefen et al., 2000). PEOU and PU has proven to be the useful theoretical base model to explain technology acceptance. Perceived usefulness and ease of use were the most notable determinants of computer user acceptance. Both of these dimensions are also an explainable component to predict the internet shoppers to evoke in e-purchasing. The three MOA variables were positively related to Online Gamers Know-How Exchange.

This support previous findings, MacInnis et al. (1991), Gruen et al. (2006, 2007) and Siemsen et al. (2008). The consistency of the findings of this study with those reported from previous studies suggests that MOA are significant variables that affect Online Gamers Know-How Exchange, regardless of whether the exchange of information for the purpose of business intentions as investigated in this study, or for other purposes such as brand evaluation information found in advertisements (MacInnis et al., 1991), know-how exchange on the video editing software applications in online communities (Gruen et al., 2006), face-to-face networking behavior in professional meetings (Gruen et al., 2007), knowledge sharing among employees or information exchanged on planning and development on local community involvement for street music festivals.

The result also shown that opportunities have a significant effect on Online Gamers Know-How Exchange, which is quite consistent with previous studies on further investigation revealed that this study followed Gruen et al. (2006, 2007) studied the opportunities measured in depth by using ten items, including distraction, time available, conductive context, and ability to affiliate, compared with Briliana et al. (2015) which uses two items covering time spent and internet access, which uses four items that include awareness of meetings and community forums, interest by local organizers and local government in the view of hearing, representing respondents and other local community views, and opportunities to contribute to festival decision-making.

\section{Conclussion}

Marketers can determine the Online Gamers Know-How Exchange effect by checking the community where the gamers is a member. This study provides evidence where businesses in the gaming industry can now narrow their focus areas into four categories; technology acceptance, MOA and Online Gamers Know-How Exchange. This pattern shows; increased technology acceptance and MOA, will drive Online Gamers Know-How Exchange process, which then leads to the transaction process. These factors, each on a particular function can be assessed to understand the priority of the necessary improvements in the current business conditions. In addition, interaction between players can be applied to control, manipulate and predict future behavior; simply by assessing how effective the current knowledge exchange process. This in return, will improve the overall efficiency of the company in dealing with customers. Further investigation revealed that this study followed Gruen et al. $(2006,2007)$ studied the opportunities measured in depth by using ten items, including distraction, time available, conductive context, and ability to affiliate, compared with Briliana et al. (2015) which uses two items covering time spent and internet access.

\section{References}


Hall.

Ajzen, I. (1991). The theory of planned behavior. Organizational behavior and human decision processes, 50(2), 179-211.

Ang, S., Van Dyne, L., Koh, C., Ng, K. Y., Templer, K. J., Tay, C., and Chandrasekar, N. A. (2007). Cultural Intelligence: Its Measurement and Effects on Cultural Judgment and Decision Making, Cultural Adaptation and Task Performance. Management and Organization Review, 3(3), 335-371.

Briliana, V., Wahid, N. A., and Fernando, Y. (2015). The Effect of Motivation, Opportunity, Ability and Social Identity Towards Customer-To-Customer Online Know-How Exchange. Advanced Science Letters, 21(4), 819-822.

Chin, W. W. (1998). The Partial Least Squares Approach To Structural Equation Modeling. Modern Methods for Business Research, 295(2), 295-336.

Gefen, D., Straub, D., and Boudreau, M. C. (2000). Structural Equation Modeling Techniques and Regression: Guidelines for Research Practice. Communications of AIS, 4(7), 79-89.

Gruen, T. W. (2005). How E-Communities Extend the Concept of Exchange in Marketing: An application of the Motivation, Opportunity, Ability (MOA) Theory. Marketing Theory, 5(1), 33-49.

Gruen, T. W., Osmonbekov, T., and Czaplewski, A. J. (2006). eWOM: The Impact of Customer-To-Customer Online Know-How Exchange on Customer Value and Loyalty. Journal of Business Research, 59(4), 449-456.

Gruen, T. W., Osmonbekov, T., and Czaplewski, A. J. (2007). Customer-to-customer exchange: Its MOA antecedents and its impact on value creation and loyalty. Journal of the Academy of Marketing Science, 35(4), 537-549.

Hanson, W. E., Creswell, J. W., Clark, V. L. P., Petska, K. S., and Creswell, J. D. (2005). Mixed Methods Research Designs in Counseling Psychology. Journal of Counseling Psychology, 52(2), 224-231.

Hamari, J. (2015). Why do people buy virtual goods? Attitude toward virtual good purchases versus game enjoyment. International Journal of Information Management, 35(3), 299-308.

Hamari, J., and Sjöblom, M. (2017). What is eSports and why do people watch it?. Internet research. 2(3), 1-34.

Herrewijn, L., and Poels, K. (2013). Putting Brands Into Play: How Game Difficulty and Player Experiences Influence the Effectiveness of in-Game Advertising. International Journal of Advertising, 32(1), 17-44.

Koo, D. M. (2009). The Moderating Role of Locus of Control on the Links between Experiential Motives and Intention to Play Online Games. Computers in Human Behavior, 25(2), 466-474.

Liang, T. P., and Yeh, Y. H. (2011). Effect of use Contexts on the Continuous use of Mobile Services: The Case of Mobile Games. Personal and Ubiquitous Computing, 15(2),187-196.

Lu, H. P., and Wang, S. M. (2008). The Role of Internet Addiction in Online Game Loyalty: An Exploratory Study. Internet Research, 18(5), 499-519.

MacInnis, D. J., Moorman, C., and Jaworski, B. J. (1991). Enhancing and Measuring Consumers Motivation, Opportunity, and Ability to Process Brand Information from Ads. Journal of Marketing, 55(4), 32-53.

Masum, H., and Zhang, Y. C. (2004). Manifesto for the reputation society. First Monday, 9(7), 1-12.

Pinho, J. C. M. R., and Soares, A. M. (2011). Examining the Technology Acceptance Model in the Adoption of Social Networks. Journal of Research in Interactive Marketing, 5, 116-129.

Rothschild, M. L. (1999). Carrots, Sticks, and Promises: A Conceptual Framework for the Management of Public Health and Social Issue Behaviors. The Journal of Marketing, 24, 24-37.

Siemsen, E., Roth, A., and Oliveira, P. (2010). Common Method Bias in Regression Models with Linear, Quadratic, and Interaction Effects. Organizational Research Methods, 13(3), 456-476.

Wu, T. C., Scott, D., and Yang, C. C. (2013). Advanced or addicted? Exploring the relationship of recreation specialization to flow experiences and online game addiction. Leisure Sciences, 35(3), 203-217. 